\title{
Genetic detection of free cancer cells in the peritoneal cavity of the patient with gastric cancer: present status and future perspectives
}

\author{
Yoshiyuki Fujiwara, Yuichiro Doki, Hirokazu Taniguchi, Itsuro Sohma, Shuji Takiguchi, Hiroshi Miyata, \\ Makoto Yamasaki, and Morito Monden \\ Department of Gastroenterological Surgery, Graduate School of Medicine, Osaka University, 2-2 Yamadaoka (E-2), Suita 565-0871, Japan
}

\begin{abstract}
The purpose of this review is to examine the current status and future perspectives of the molecular analysis of peritoneal lavage fluid in patients with gastric cancer. During the past 10 years, the polymerase chain reaction $(\mathrm{PCR})$ has been applied for the molecular detection of free cancer cells in the abdominal cavity of patients with gastric cancer, and its clinical significance in establishing the presence of peritoneal dissemination has been assessed by several groups especially in Japan. The majority of these studies have confirmed the predictive value of the molecular detection of peritoneal metastasis and recurrence using peritoneal lavage fluid. Based on these findings, since April 2006, the genetic diagnosis of body fluids has been included in the Japanese Government public health insurance program for patients with solid tumors. However, there are still many obstacles to overcome before the genetic diagnosis of micrometastasis can be considered a routine laboratory assay. Here we review the importance of the molecular detection of cancer cells in the abdominal cavity, and the molecular techniques used for such diagnosis; we also provide some clinical examples to illustrate the value of molecular diagnosis.
\end{abstract}

Key words Gastric cancer - Peritoneal dissemination · Micrometastasis $\cdot$ Molecular biology $\cdot$ RT-PCR $\cdot$ TRC

\section{Introduction}

The prognosis of advanced gastric cancer, especially that of serosa-invading tumors, remains poor even after curative operation, and in these patients, peritoneal dissemination, mainly caused by the seeding of free cancer cells from the primary gastric cancer, is the most common type of spread $[1,2]$. Table 1 shows the frequency and type of recurrence, according to the depth of tumor invasion within the gastric wall, in 752 patients with gastric cancer treated with curative resection at the Department of Gastroenterological Surgery, Osaka University Hospital. The peritoneum was the most frequent site of recurrence in patients with gastric cancer who received curative resection $(34.3 \%)$. Furthermore, the frequency increased with increased depth of invasion of the gastric wall (subserosal invasion, 34.9\%; serosal invasion, $46.7 \%$; and invasion of adjacent organs, $60.0 \%)$.

At present, cytological examination of peritoneal lavage fluid collected at laparotomy is performed to predict peritoneal spread [3-5], and this procedure has been incorporated in the Japanese staging system for gastric cancer [6]. The majority of patients with positive cytology on peritoneal lavage develop peritoneal metastasis, although the latter also occurs in patients with negative cytological results [3-5]. These results indicate that the conventional cytological examination lacks sensitivity for the detection of residual cancer cells and prediction of peritoneal spread.

Molecular diagnosis using reverse transcriptasepolymerase chain reaction (RT-PCR) analysis has been used recently for the detection of cancer micrometastases [7-9]. RT-PCR is more sensitive than conventional cytological examination [10-12]. Based on several studies, the results of RT-PCR of peritoneal lavage fluid correlate strongly with peritoneal recurrence and prognosis after curative surgery in patients with advanced gastric cancer [10, 12-17].

In this article, we review the present status and future perspectives of molecular analysis of peritoneal lavage in patients with gastric cancer. We also describe our preliminary results and their possible clinical application. 
Table 1. Recurrence sites after curative resection of gastric cancer, according to depth of invasion in the gastric wall

\begin{tabular}{|c|c|c|c|c|c|c|c|c|}
\hline \multirow[b]{2}{*}{ Depth } & \multirow[b]{2}{*}{ Number } & \multicolumn{7}{|c|}{ Site of recurrence } \\
\hline & & Peritoneum & Lymph node & Liver & Distant & Local & Stomach & Unknown \\
\hline $\mathrm{m}$ & 3 & $0(0)$ & $1(33.3)$ & $1(33.3)$ & $0(0)$ & $0(0)$ & $0(0)$ & $1(33.3)$ \\
\hline $\mathrm{sm}$ & 11 & $1(9.1)$ & $3(27.3)$ & $1(9.1)$ & $1(9.1)$ & $1(9.1)$ & $0(0)$ & $4(36.4)$ \\
\hline $\mathrm{mp}$ & 8 & $0(0)$ & $0(0)$ & $1(12.5)$ & $1(12.5)$ & $1(12.5)$ & $1(12.5)$ & $4(50.0)$ \\
\hline SS & 43 & $15(34.9)$ & $8(18.6)$ & $6(14.0)$ & $3(7.0)$ & $3(7.0)$ & $1(2.3)$ & $7(16.3)$ \\
\hline se & 30 & $14(46.7)$ & 4 (13.3) & $3(10.0)$ & 4 (13.3) & $0(0)$ & $0(0)$ & 5 (16.7) \\
\hline \multirow[t]{2}{*}{ si } & 10 & $6(60.0)$ & $0(0)$ & $1(10.0)$ & $1(10.0)$ & $0(0)$ & $0(0)$ & $2(20.0)$ \\
\hline & 105 & $36(34.3)$ & $16(15.2)$ & $13(12.4)$ & $10(9.5)$ & $5(4.8)$ & $2(1.9)$ & $23(21.9)$ \\
\hline
\end{tabular}

$n=752$ Patients

Figures in parentheses are percentages

Table 2. Representative reports on molecular diagnosis with peritoneal lavage fluid in gastric cancer

\begin{tabular}{|c|c|c|c|c|}
\hline Year & Author & Method & Marker & Clinical associations \\
\hline 1997 & Nakanishi [12] & RT-PCR & CEA & \\
\hline 1998 & Fujimura [47] & IHC \& RT-PCR & Trypsinogen & \\
\hline 1998 & Kodera $[16]$ & RT-PCR & CEA & Peritoneal recurrence; survival \\
\hline 2000 & Mori [25] & TRAP assay & Telomerase & \\
\hline 2000 & Nakanishi [13] & Q-RT-PCR & CEA & \\
\hline 2001 & Yonemura [14] & RT-PCR & MMP-7 & Peritoneal recurrence; survival \\
\hline 2001 & Yonemura [48] & RT-PCR & CEA & Peritoneal recurrence; survival \\
\hline 2002 & Kodera [17] & Q-RT-PCR & CEA & Survival \\
\hline 2003 & Sugita [10] & Q-RT-PCR & CEA \& CK-20 & Peritoneal recurrence; survival \\
\hline 2004 & Oyama [49] & Q-RT-PCR & CEA & Peritoneal recurrence \\
\hline 2004 & Sakakura [26] & Q-RT-PCR & Dopa decarboxylase & \\
\hline 2004 & Shimomura [27] & Q-RT-PCR & L-3 phosphoserine phosphatase heparanase & \\
\hline 2005 & Wang [35] & RT-PCR & CEA & \\
\hline 2005 & Ito [50] & Q-RT-PCR & CEA & Peritoneal recurrence; survival \\
\hline 2005 & Kodera [11] & Q-RT-PCR & CEA \& CK-20 & Survival \\
\hline 2007 & Mori [28] & RT-PCR+DNA array & & \\
\hline
\end{tabular}

Q-RT-PCR, Quantitative RT-PCR

\section{Significance of micrometastasis in lymph node, blood, and bone marrow specimens of patients with gastric cancer}

Occult tumor cells in gastric cancer, missed by conventional pathological examination and detected by PCR or immunohistochemistry, have been studied for more than 10 years. Micrometastasis in lymph nodes obtained from gastric cancer surgery has been frequently assessed, especially with immunohistochemical analysis. However, the clinical impact of micrometastasis in dissected lymph nodes in gastric cancer has been controversial [18-21]. Although the detection of cancer cells in peripheral blood and bone marrow specimens has also been reported in gastric cancer, the clinical impact on patient prognosis and disease recurrence has not been clarified [22-24].

\section{Molecular approach to the detection of free cancer cells in peritoneal lavage}

The most common method for the detection of cancer cells in peritoneal lavage is the amplification of messenger RNA (mRNA) that is specific to epithelial cells or cancer cells, by RT-PCR. In this method, peritoneal lavage specimens are centrifuged and the cell pellets are subjected to RNA isolation. The RT-PCR technique has been widely used for the amplification and detection of target RNA molecules. Table 2 lists studies of the genetic diagnosis of peritoneal lavage in patients with gastric cancer, together with the molecular markers used for the detection of free cancer cells in the peritoneal cavity. Carcinoembryonic antigen (CEA) mRNA has been commonly used for RT-PCR-based molecular detection. However, some gastric cancer tumors do not express CEA mRNA and additional markers such as cytokeratins were also used in some studies [10,11]. Other markers, such as matrix metalloproteinase-7 
(MMP-7) and telomerase activity were also used, because these molecules play an important role in cancer cell invasion and survival $[14,25]$. Other candidate molecular markers have also been identified, such as dopa decarboxylase and L-3 phosphoserine phosphatase, which are overexpressed in gastric cancer cell lines and silenced in normal gastric mucosa, as demonstrated by microarray analysis [26, 27]. Recently, Mori et al. [28] developed a novel molecular method of a miniarray-based multiple-marker assay for peritoneal lavage micrometastasis, which combines RT-PCR and miniarray detection. Over the past 5 years, a quantitative PCR system with continuous fluorescence monitoring of PCR products has been introduced to allow accurate quantification of the initial template copy number of target molecules [10, 17]. The LightCycler (Roche Diagnostics, Basel, Switzerland) has been widely used worldwide as a rapid, quantitative thermal cycler. In this system, the fluorescence produced from doublestrand DNA-binding fluorescence dye is monitored once per cycle (real time) and the standard's amplification curve is identified with control specimens, which enables the operator to quantify the relative number of cancer cells in the reaction tube. The thermal cycler also uses small capillary tubes, which allows a rapid change in reaction temperatures. With these advantages, the system has enhanced the reliability and rapidity of genetic diagnosis with the PCR system (Fig. 1), which encouraged us to introduce it for clinical use.
Table 2 provides a review of studies that examined the clinical significance of the molecular diagnosis of peritoneal lavage in gastric cancer. Most of these reports emphasized the clinical significance of molecular diagnosis using peritoneal lavage fluid in gastric cancer, especially for predicting peritoneal recurrence and survival time.

\section{Clinical significance of molecular diagnosis of peritoneal spread}

In the studies listed in Table 2, peritoneal molecular diagnosis at surgery was closely correlated with clinicopathological parameters. Table 3 shows the correlation between the results of RT-PCR using peritoneal lavage collected at laparotomy and various clinical parameters at our institute. Genetic diagnosis was correlated with lymph node metastasis, depth of invasion of the gastric wall, stage classification, $\mathrm{P}$ factor (peritoneal metastasis) and CY factor (peritoneal lavage cytology). Figure 2 shows the overall survival and peritoneal recurrencefree survival curves of patients with serosa-invading gastric tumors, based on the results of peritoneal lavage diagnosis using cytology and RT-PCR at surgery. The prognosis of patients with positive cytology in the peritoneal lavage was very poor, and most patients died within 1 year after surgery. Among the patients with negative cytology, those with a positive genetic diagno-

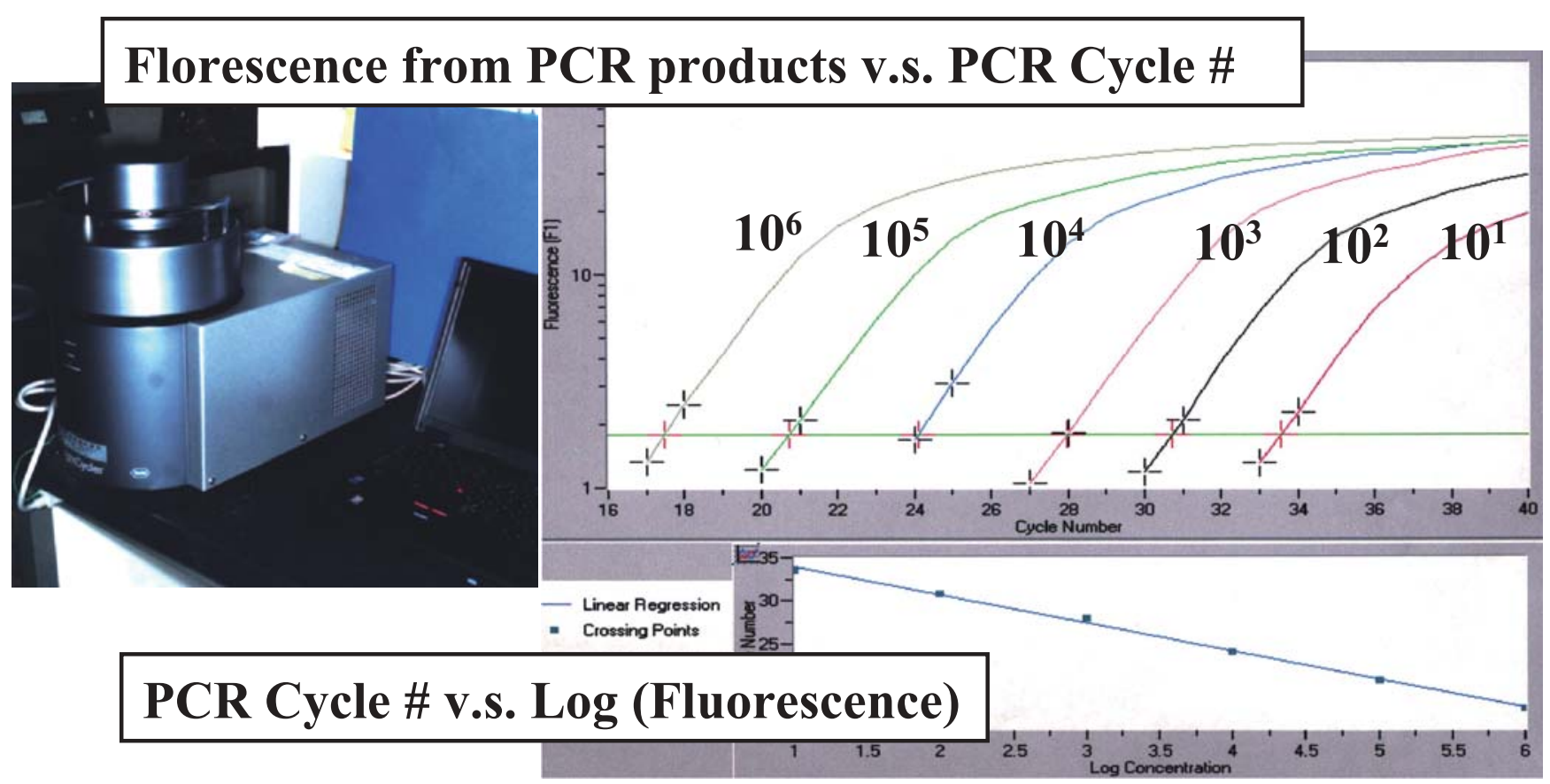

Fig. 1. The quantitative polymerase chain reaction $(P C R)$ system with the LightCycler (Roche Diagnostics, Basel, Switzerland). The intensity of fluorescence produced from PCR products was calculated at each thermal cycle and a standard curve was constructed using serial dilutions of control cancer cell lines 
sis had a significantly poorer prognosis than those with negative genetic results. Follow-up analysis showed that more than half of the patients with positive PCR and CY0 developed peritoneal recurrence after surgery, while almost all patients with negative PCR and CY0 had no peritoneal recurrence after surgery. Based on these results, we conclude that molecular diagnosis using peritoneal lavage fluid is useful to predict peritoneal recurrence for patients with serosal invasion of gastric tumors.

Table 3. Correlations between genetic diagnosis with peritoneal lavage fluid and clinocopathological features

\begin{tabular}{lrrr}
\hline & \multicolumn{2}{c}{ Genetic diagnosis } & \\
\cline { 2 - 2 } & Negative & Positive & $P$ value \\
\hline Lymph node metastasis & & & \\
$(-)$ & 45 & 18 & \\
$(+)$ & 25 & 32 & 0.0022 \\
Depth of invasion & 43 & 14 & \\
pT1 & 18 & 20 & \\
pT2 & 8 & 13 & \\
pT3 & 1 & 4 & 0.0016 \\
pT4 & 59 & 30 & \\
Stage & 11 & 28 & $<0.0001$ \\
I, II & & & \\
III, IV & 70 & 46 & \\
P factor & 0 & 12 & $<0.0001$ \\
P0 & & & \\
P1 & 68 & 46 & \\
CY factor & 0 & 9 & 0.0005 \\
$\quad$ CY0 & & & \\
CY1 & & & \\
\hline
\end{tabular}

A

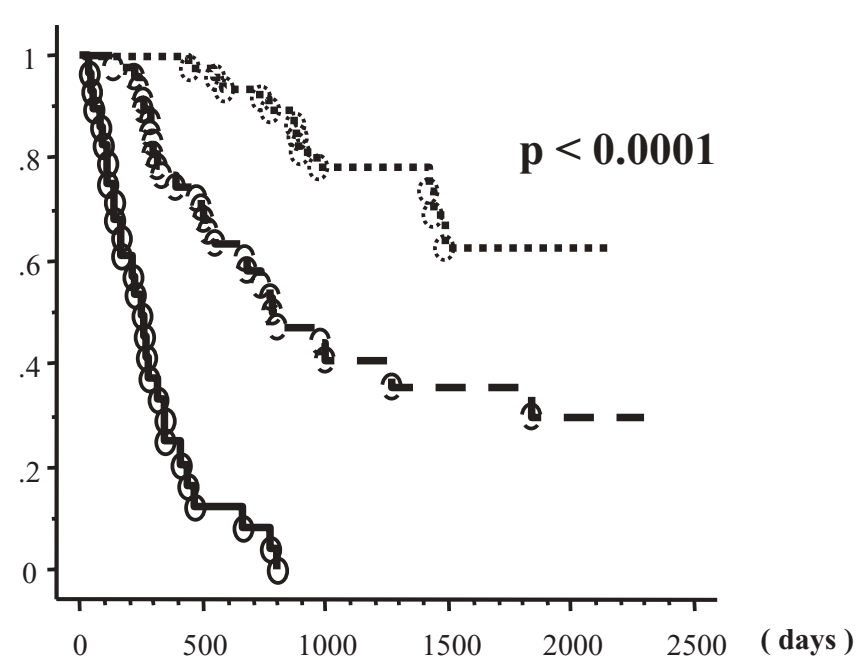

\section{Immunocytochemical analysis using peritoneal lavage specimens}

In addition to the above PCR-based methods, some groups have used immunocytochemical analysis to detect cancer cells in peritoneal lavage [29,30]. Nekarda et al. [31] reported the frequent detection of free peritoneal tumor cells by immunocytochemistry with the monoclonal antibody Ber-EP4. According to their report, $34 \%$ of patients with serosa-invaded tumors showed the presence of free cancer cells by immunocytochemistry. Furthermore, the free cancer cells detected by immunocytochemistry were shown to be an independent prognostic factor in gastric cancer.

\section{Tumor markers in peritoneal lavage specimens}

Tumor markers, including the CEA level, were examined in peritoneal lavage fluid and the associations with prognosis and peritoneal recurrence were assessed [32, 33]. Yamamoto et al. [34] evaluated the tumor markers CEA, carbohydrate antigen (CA) 125, and CA19-9 in peritoneal lavage fluid, using a chemiluminescent enzyme immunoassay. They concluded that CEA was the most reliable tumor marker in peritoneal lavage fluid for peritoneal dissemination in gastric cancer. However, Wang et al. [35] compared the results of an RT-PCR assay with CEA and a combination of cytology and peritoneal CEA assay (pCEA)and they concluded that the RT-PCR assay with CEA was more sensitive than the combination of cytology and pCEA.

\section{B}

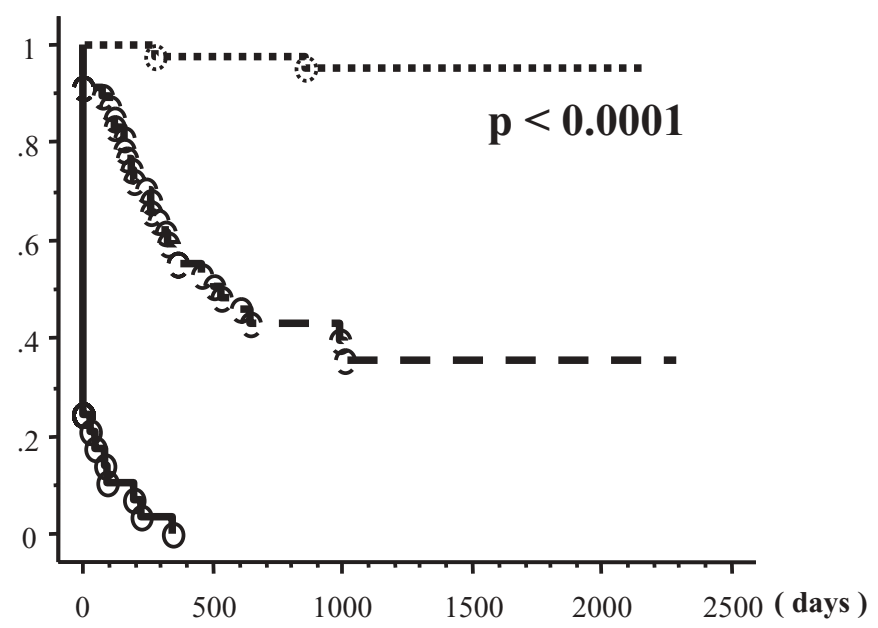

Fig. 2. Overall survival curves (A) and peritoneal recurrence-free survival curves $(\mathbf{B})$ of 123 patients with serosa-invading gastric cancer, based on the results of cytology and reverse transcriptase (RT)-PCR with peritoneal lavage. Dotted line, CY0, PCR (-), $n=47$; dashed line, CY0, PCR (+), $n=47$; continuous line, CY1, $n=29$ 


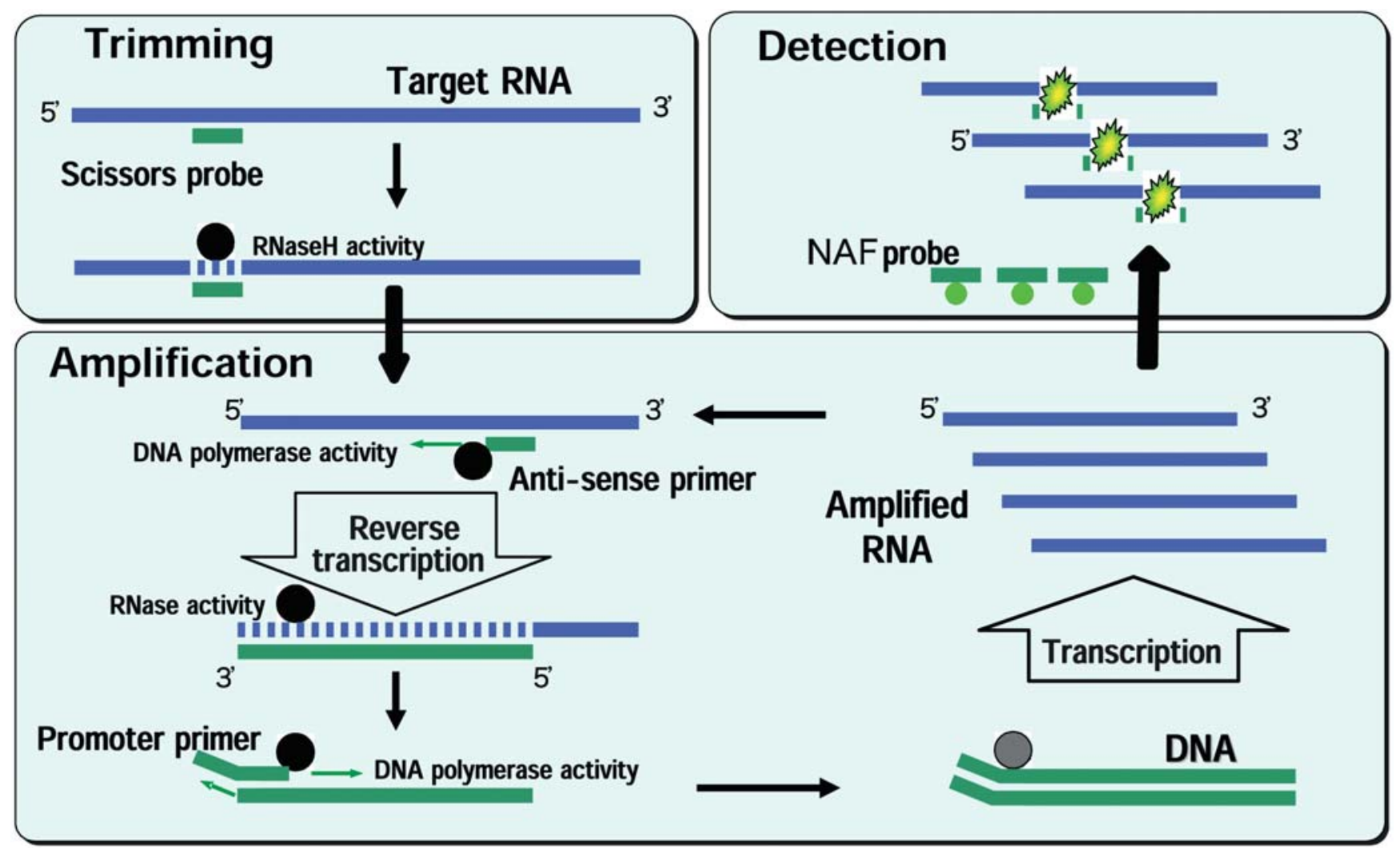

Fig. 3. The elementary steps of the transcription-reverse transcription concerted reaction (TRC) for the detection of target mRNAs. The reaction performs RNA sequence amplification isothermally in the presence of the carcinoembryonic antigen (CEA)-specific intercalation activating fluorescence (INAF)

\section{Novel molecular techniques for detection of micrometastasis}

New simple and rapid molecular techniques for the detection of target mRNAs have been developed in recent years. One of the promising techniques is the reverse transcription loop-mediated isothermal amplification (RT-LAMP) reaction, a novel technique designed to detect mRNA expression of targeted sequences with high sensitivity and rapidity. Horibe and coworkers [36] reported the usefulness of the method with cytokeratin19 as a marker for the detection of micrometastasis in dissected lymph nodes of gastric cancer. The method does not need the RNA extraction phase and uses homogenized crude specimens, which can improve the rapidity, with the method taking $1 \mathrm{~h}$ or less [36].

We have also developed a novel molecular diagnostic technique with another RNA amplification system called transcription-reverse transcription concerted reaction (TRC). The method amplifies the target mRNAs directly without the reverse-transcription step in a one-tube reaction, by isothermal amplification with RNA polymerase. The TRC method is superior to the probe. The progress of the reaction is monitored by measuring the fluorescence intensity from RNA products The TRC method consists of three steps: (1) trimming, (2) amplification, and (3) detection. Black dots, reverse transcriptase; gray dots, T7 RNA polymerase

RT-PCR method in rapidity and simplicity (Fig. 3) [37]. We applied the method with CEA as a marker for the detection of free cancer cells in peritoneal washes. The sensitivity and quantification of the TRC reaction for the detection of occult cancer cells in peritoneal washes were comparable to those of the conventional quantitative RT-PCR with the LightCycler [37]. It is anticipated that these post-PCR diagnostic systems will contribute to the clinical application of genetic diagnosis in the near future.

\section{Limitation of the molecular approach for the detection of micrometastasis}

One major issue with the molecular approach to the detection of micrometastasis relates to the problem of false-positive diagnosis. Several reports have pointed out the limitation of the RT-PCR technique because of the high false-positive rates [38]. The false-positive results could be attributed to one of the following two factors: it could be that these positive results are due to the illegitimate expression of marker genes in noncan- 
cerous cells $[39,40]$. The second reason for the falsepositive result arises from the inherent properties of molecular diagnostic techniques; i.e., their high sensitivity and ability to detect marker gene(s) in only a few cancer cells that are otherwise clinically insignificant, as they are unlikely to form metastases.

\section{Clinical application of molecular diagnostic techniques}

Based on the results that showed the predictive value of molecular diagnosis of metastatic spread into the peritoneum, we introduced molecular diagnosis as a routine clinical tool in gastric cancer [41]. Preoperative peritoneal lavage diagnosis is applied at the time of the staging laparoscopy for advanced gastric cancer with serosa-invading tumors. Patients with CY0 who are RTPCR-positive receive short-term intraperitoneal chemotherapy through a 14-Fr gastric tube inserted into the abdominal cavity at the time of staging laparoscopy [41]. Molecular diagnostic techniques using peritoneal lavage are applied at the time of surgical resection, which is usually conducted after chemotherapy. The prognosis of patients who showed a change in the result of genetic diagnosis from positive to negative was significantly improved compared to those who remained positive after chemotherapy. This result suggests that genetic diagnosis can be useful for predicting the effect of chemotherapy, in addition to the prediction of a high risk of peritoneal recurrence. Yamamoto et al. [42] introduced the procedure of extensive intraoperative peritoneal lavage (EIPL) and a rapid RT-PCR detection system with CEA and cytokeratin (CK)-20. The RTPCR of EIPL fluid performed after surgery frequently detected positive results, especially in patients with lymph node metastasis, leading to the speculation that lymph node dissection could have opened the lymphatic channels, resulting in the spread of viable cancer cells into the peritoneal cavity. Yamamoto et al. [42] concluded that one advantage of EIPL was that it reduced the number of cancer cells analyzed by quantitative RTPCR and might thus improve prognosis. Although further investigations will be needed to assess the usefulness of EIPL for gastric cancer with lymph node metastasis, the introduction of quantitative molecular diagnosis may possibly improve the management of cancer treatment.

\section{Future perspectives of peritoneal lavage diagnosis by genetic techniques}

In advanced gastric cancer, the peritoneum is the most common site of metastasis and recurrence. Furthermore, it is often difficult to diagnose peritoneal dis- semination at an early stage and to treat such patients. For these reasons, the use of molecular diagnosis with peritoneal lavage fluid has been investigated extensively during the past 10 years, especially in patients with gastric cancer (Table 2). As we have shown here, there is compelling evidence for the utility of genetic techniques in the diagnosis of metastasis and spread in the peritoneum. Using genetic techniques, we can select patients at high risk as well as those at low risk for peritoneal recurrence. For high-risk patients, more aggressive chemotherapy such as intraperitoneal chemotherapy or chemohyperthermia may be justifiable to prevent peritoneal recurrence [43-45]. Recent clinical trials from Japan have reported the significance of chemotherapy with S-1, a novel oral fluoropyrimidine derivative, after curative surgery [46]. Based on the results of these trials, the oral administration of S-1 for 1 year has been recommended for patients with stage II and stage III gastric cancer [46]. However, the adverse effects and the high medical costs of S- 1 chemotherapy make this treatment not suitable for all patients. In fact, one-third of patients who were scheduled for S-1 chemotherapy could not complete the entire course of such therapy [46]. Therefore, patients identified as low-risk, based on genetic diagnosis, could be excluded from such chemotherapy after curative resection.

In April 2006, the Japanese Government included the genetic diagnosis of body fluids in the public health insurance program for patients with solid tumors. This step has facilitated the introduction into clinical practice of genetic diagnostic techniques for peritoneal lavage from patients with gastric cancer. However, at present, genetic diagnosis can be performed only at University hospitals and large cancer centers. To make genetic diagnosis a routine service, methods of molecular diagnosis, which now show many differences among institutions, will need to be standardized, and simple diagnostic devices and commercially based kits should be available for laboratory technicians. Furthermore effective treatments for patients with a positive peritoneal molecular diagnosis need to be developed by multiinstitutional trials.

\section{References}

1. Dupont JB, Lee JR, Burton GR, Cohn I Jr. Adenocarcinoma of the stomach: review of 1497 cases. Cancer 1978;41:941-7.

2. Yamada E, Miyaishi S, Nakazato H, Kato K, Kito T, Takagi H, et al. The surgical treatment of cancer of the stomach. Int Surg 1980;65:387-99.

3. Bando E, Yonemura Y, Takeshita Y, Taniguchi K, Yasui T, Yoshimitsu Y, et al. Intraoperative lavage for cytological examination in 1297 patients with gastric carcinoma. Am J Surg 1999;178:256-62. 
4. Bonenkamp JJ, Songun I, Hermans J, van de Velde CJ. Prognostic value of positive cytology findings from abdominal washings in patients with gastric cancer. Br J Surg 1996;83:672-4.

5. Koga S, Kaibara N, Iitsuka Y, Kudo H, Kimura A, Hiraoka H. Prognostic significance of intra-peritoneal free cancer cells in gastric cancer patients. J Cancer Res Clin Oncol 1984;108:236-8.

6. Japanese Gastric Cancer Association. Japanese classification of gastric carcinoma - 2nd English edition-. Gastric Cancer 1998;1: $10-24$.

7. Noura S, Yamamoto H, Ohnishi T, Masuda N, Matsumoto T, Takayama O, et al. Comparative detection of lymph node micrometastases of stage II colorectal cancer by reverse transcriptase polymerase chain reaction and immunohistochemistry. J Clin Oncol 2002;20:4232-41.

8. Yoshioka S, Fujiwara Y, Sugita Y, Okada Y, Yano M, Tamura S, et al. Real-time rapid reverse transcriptase-polymerase chain reaction for intraoperative diagnosis of lymph node micrometastasis: clinical application for cervical lymph node dissection in esophageal cancers. Surgery 2002;132:34-40.

9. Okada Y, Fujiwara Y, Yamamoto H, Sugita Y, Yasuda T, Doki Y, et al. Genetic detection of lymph node micrometastases in patients with gastric carcinoma by multiple-marker reverse transcriptase-polymerase chain reaction assay. Cancer 2001;92: 2056-64.

10. Sugita $\mathrm{Y}$, Fujiwara $\mathrm{Y}$, Taniguchi $\mathrm{H}$, Mori T, Ishii T, Niwa H, et al. Quantitative molecular diagnosis of peritoneal lavage fluid for prediction of peritoneal recurrence in gastric cancer. Int $\mathrm{J}$ Oncol 2003;23:1419-23.

11. Kodera Y, Nakanishi H, Ito S, Yamamura Y, Fujiwara M, Koike M, et al. Prognostic significance of intraperitoneal cancer cells in gastric carcinoma: detection of cytokeratin 20 mRNA in peritoneal washes, in addition to detection of carcinoembryonic antigen. Gastric Cancer 2005;8:142-8.

12. Nakanishi H, Kodera Y, Torii A, Hirai T, Yamamura Y, Kato T, et al. Detection of carcinoembryonic antigen-expressing free tumor cells in peritoneal washes from patients with gastric carcinoma by polymerase chain reaction. Jpn J Cancer Res 1997;88: 687-92.

13. Nakanishi H, Kodera Y, Yamamura Y, Ito S, Kato T, Ezaki T, et al. Rapid quantitative detection of carcinoembryonic antigenexpressing free tumor cells in the peritoneal cavity of gastriccancer patients with real-time RT-PCR on the LightCycler. Int J Cancer 2000;89:411-7.

14. Yonemura Y, Fujimura T, Ninomiya I, Kim BS, Bandou E, Sawa T, et al. Prediction of peritoneal micrometastasis by peritoneal lavaged cytology and reverse transcriptase-polymerase chain reaction for matrix metalloproteinase-7 mRNA. Clin Cancer Res 2001;7:1647-53.

15. Schmidt P, Thiele M, Rudroff C, Vaz A, Schilli M, Friedrich K, et al. Detection of tumor cells in peritoneal lavages from patients with gastrointestinal cancer by multiplex reverse transcriptase PCR. Hepatogastroenterology 2001;48:1675-9.

16. Kodera Y, Nakanishi H, Yamamura Y, Shimizu Y, Torii A, Hirai T, et al. Prognostic value and clinical implications of disseminated cancer cells in the peritoneal cavity detected by reverse transcriptase-polymerase chain reaction and cytology. Int $\mathrm{J}$ Cancer 1998;79:429-33.

17. Kodera Y, Nakanishi H, Yamamura Y, Kanemitsu Y, Shimizu Y, Hirai T, et al. Quantitative detection of disseminated free cancer in peritoneal washes with real-time reverse transcriptase polymerase chain reaction. Ann Surg 2002;235:499-506.

18. Cai J, Ikeguchi M, Tsujitani S, Maeta M, Liu J, Kaibara N. Significant correlation between micrometastasis in the lymph nodes and reduced expression of E-cadherin in early gastric cancer. Gastric Cancer 2001;4:66-74.

19. Lee E, Chae Y, Kim I, Choi J, Yeom B, Leong AS. Prognostic relevance of immunohistochemically detected lymph node micrometastasis in patients with gastric carcinoma. Cancer 2002;94: 2867-73.
20. Fukagawa T, Sasako M, Mann GB, Sano T, Katai H, Maruyama $\mathrm{K}$, et al. Immunohistochemically detected micrometastases of the lymph nodes in patients with gastric carcinoma. Cancer 15; 2001;92:753-60.

21. Morgagni P, Saragoni L, Scarpi E, Zattini PS, Zaccaroni A, Morgagni D, et al. Lymph node micrometastases in early gastric cancer and their impact on prognosis World J Surg 2003;27: 558-61.

22. Maehara Y, Yamamoto M, Oda S, Baba H, Kusumoto T, Ohno $\mathrm{S}$, et al. Cytokeratin-positive cells in bone marrow for identifying distant micrometastasis of gastric cancer. Br J Cancer 1996;73: 83-7.

23. Macadam R, Sarela A, Wilson J, MacLennan K, Guillou P. Bone marrow micrometastases predict early post-operative recurrence following surgical resection of oesophageal and gastric carcinoma. Eur J Surg Oncol 2003;29:450-4.

24. Chen XM, Chen GY, Wang ZR, Zhu FS, Wang XL, Zhang X. Detection of micrometastasis of gastric carcinoma in peripheral blood circulation World J Gastroenterol 2004;10:804-8.

25. Mori N, Oka M, Hazama S, Iizuka N, Yamamoto K, Yoshino S, et al. Detection of telomerase activity in peritoneal lavage fluid from patients with gastric cancer using immunomagnetic beads. Br J Cancer 2000;83:1026-32.

26. Sakakura C, Takemura M, Hagiwara A, Shimomura K, Miyagawa $\mathrm{K}$, Nakashima S, et al. Overexpression of dopa decarboxylase in peritoneal dissemination of gastric cancer and its potential as a novel marker for the detection of peritoneal micrometastases with real-time RT-PCR. Br J Cancer 2004;90:665-71.

27. Shimomura K, Sakakura C, Takemura M, Takagi T, Fukuda K, Kin S, et al. Combination of L-3-phosphoserine phosphatase and CEA using real-time RT-PCR improves accuracy in detection of peritoneal micrometastasis of gastric cancer. Anticancer Res 2004;24:1113-20.

28. Mori K, Suzuki T, Uozaki H, Nakanishi H, Ueda T, Matsuno Y, et al. Detection of minimal gastric cancer cells in peritoneal washings by focused microarray analysis with multiple markers: clinical implications. Ann Surg Oncol 2007;14:1694-702.

29. Benevolo M. Diagnostic and prognostic value of peritoneal immunocytology in gastric cancer. J Clin Oncol 1998;16: 3406-11.

30. Vogel P, Ruschoff J, Kummel S, Zirngibl H, Hofstadter F, Hohenberger $\mathrm{W}$, et al. Immunocytology improves prognostic impact of peritoneal tumour cell detection compared to conventional cytology in gastric cancer. Eur J Surg Oncol 1999;25: 515-9.

31. Nekarda H, Gess C, Stark M, Mueller JD, Fink U, Schenck U, et al. Immunocytochemically detected free peritoneal tumour cells (FPTC) are a strong prognostic factor in gastric carcinoma. Br J Cancer 1999;79:611-9.

32. Abe N, Watanabe T, Toda H, Machida H, Suzuki K, Masaki T, et al. Prognostic significance of carcinoembryonic antigen levels in peritoneal washes in patients with gastric cancer. Am J Surg 2001;181:356-61.

33. Nishiyama M, Takashima I, Tanaka T, Yoshida K, Toge T, Nagata $\mathrm{N}$, et al. Carcinoembryonic antigen levels in the peritoneal cavity: useful guide to peritoneal recurrence and prognosis for gastric cancer. World J Surg 1995;19:133-7; discussion 137.

34. Yamamoto M, Baba H, Kakeji Y, Endo K, Ikeda Y, Toh Y, et al. Prognostic significance of tumor markers in peritoneal lavage in advanced gastric cancer. Oncology 2004;67:19-26.

35. Wang JY, Lin SR, Lu CY, Chen CC, Wu DC, Chai CY, et al. Gastric cancer cell detection in peritoneal lavage: RT-PCR for carcinoembryonic antigen transcripts versus the combined cytology with peritoneal carcinoembryonic antigen levels. Cancer Lett 2005;223:129-35.

36. Horibe D, Ochiai T, Shimada H, Tomonaga T, Nomura F, Gun M, et al. Rapid detection of metastasis of gastric cancer using reverse transcription loop-mediated isothermal amplification. Int J Cancer 2007;120:1063-9. 
37. Ishii T, Fujiwara Y, Ohnaka S, Hayashi T, Taniguchi H, Takiguchi $\mathrm{S}$, et al. Rapid genetic diagnosis with the transcription-reverse transcription concerted reaction system for cancer micrometastasis. Ann Surg Oncol 2004;11:778-85.

38. Ko Y, Klinz M, Totzke G, Gouni-Berthold I, Sachinidis A, Vetter $\mathrm{H}$. Limitations of the reverse transcription-polymerase chain reaction method for the detection of carcinoembryonic antigenpositive tumor cells in peripheral blood. Clin Cancer Res 1998;4: 2141-6.

39. Ko Y, Grunewald E, Totzke G, Klinz M, Fronhoffs S, Gouni-Berthold I, et al. High percentage of false-positive results of cytokeratin 19 RT-PCR in blood: a model for the analysis of illegitimate gene expression. Oncology 2000;59:81-8.

40. Goeminne JC, Guillaume T, Salmon M, Machiels JP, D'Hondt V, Symann M. Unreliability of carcinoembryonic antigen (CEA) reverse transcriptase-polymerase chain reaction (RT-PCR) in detecting contaminating breast cancer cells in peripheral blood stem cells due to induction of CEA by growth factors. Bone Marrow Transplant 1999;24:769-75.

41. Mori T, Fujiwara Y, Sugita Y, Azama T, Ishii T, Taniguchi K, et al. Application of molecular diagnosis for detection of peritoneal micrometastasis and evaluation of preoperative chemotherapy in advanced gastric carcinoma. Ann Surg Oncol 2004;11:14-20.

42. Yamamoto K, Shimada S, Hirota M, Yagi Y, Matsuda M, Baba H. EIPL (extensive intraoperative peritoneal lavage) therapy significantly reduces peritoneal recurrence after pancreatectomy in patients with pancreatic cancer. Int J Oncol 2005;27:13218.

43. Fujimoto S, Shrestha RD, Kokubun M, Ohta M, Takahashi M, Kobayashi K, et al. Intraperitoneal hyperthermic perfusion com- bined with surgery effective for gastric cancer patients with peritoneal seeding. Ann Surg 1988;208:36-41.

44. Hamazoe R, Maeta M, Kaibara N. Intraperitoneal thermochemotherapy for prevention of peritoneal recurrence of gastric cancer. Final results of randomized controlled study. Cancer 1994; 73:2048-52.

45. Armstrong DK, Bundy B, Wenzel L, Huang HQ, Baergen R, Lele $\mathrm{S}$, et al. Intraperitoneal cisplatin and paclitaxel in ovarian cancer. N Engl J Med 2006;354:34-43.

46. Sakuramoto S, Sasako M, Yamaguchi T, Kinoshita T, Fujii M, Nashimoto A, et al. Adjuvant chemotherapy for gastric cancer with S-1, an oral fluoropyrimidine. N Engl J Med 2007;357: 1810-20.

47. Fujimura T, Ohta T, Kitagawa H, Fushida S, Nishimura GI, Yonemura $\mathrm{Y}$, et al. Trypsinogen expression and early detection for peritoneal dissemination in gastric cancer. J Surg Oncol 1998;69:71-5.

48. Yonemura Y, Endou Y, Fujimura T, Fushida S, Bandou E, Kinoshita K, et al. Diagnostic value of preoperative RT-PCRbased screening method to detect carcinoembryonic antigenexpressing free cancer cells in the peritoneal cavity from patients with gastric cancer. ANZ J Surg 2001;71:521-8.

49. Oyama K, Terashima M, Takagane A, Maesawa C. Prognostic significance of peritoneal minimal residual disease in gastric cancer detected by reverse transcription-polymerase chain reaction. Br J Surg 2004;91:435-43.

50. Ito S, Nakanishi H, Kodera Y, Mochizuki Y, Tatematsu M, Yamamura Y. Prospective validation of quantitative CEA mRNA detection in peritoneal washes in gastric carcinoma patients. Br J Cancer 2005;93:986-92. 